\title{
Entrainment ratio analysis of compress/ejector refrigeration system
}

\author{
Jiangming Tan, Jianwen Wang \\ Department of mechanical engineering, East China University of Science and Technology, \\ Shanghai, 200237, China
}

Keywords: Ejector, fluid simulation, working conditions, entrainment ratio.

\begin{abstract}
Entrainment ratio is one of the main characteristic parameters of ejector. Studding on it is of a quiet importance to the compression/ejector refrigeration system. Computational Fluid Dynamics (CFD) is used to simulate the inner flow and analyse the influence of driving fluid pressure and outlet pressure to the performance of ejector. By simulating the relations between driving fluid pressure, working fluid pressure, outlet fluid pressure and entrainment ratio are obtained. The conclusion provides valuable guiding significance for the working conditions setting.
\end{abstract}

\section{Introduction}

Ejector is an ingenious device with no direct mechanical energy consumption but continuously pumping fluid into the refrigeration system and raising the driving fluid pressure at the same time. Its structure is very simple and its operation is very stable. Ejector has been applied in many fluid engineering fields. Typical structure of ejector shows in figure 1.

It is well known that entrainment ratio $u$ and COP (efficiency of performance) are the main characteristic parameters of ejector. The factors which influence the entrainment ratio include structural parameters and operating conditions. Researches on the structural parameters are considerable, such as diameter of nozzle, length of nozzle, convergent angle of mixing chamber entry, length of diffuser and divergent angle ${ }^{[1-2]}$.As for the study of operating conditions, most of the researchers focus on the analysis of working fluid or outlet pressure. The reference [3] concludes that through the observation of figure on Mach number, it is obvious that when working fluid pressure increases, the working fluid jet centre area increased, so the entrainment ratio reduces and the critical back pressure increases. Some researchers have studied the effects of driving fluid on ejector's behaviour, but most of them did the study merely based on pure jet refrigeration system in which the difference between working fluid pressure and driving fluid pressure is great and up to dozens or even hundreds of times ${ }^{[1-4]}$.For the pure ejector refrigeration system, driving fluid pressure and it's velocity can only adjust in a narrow range. Moreover, the pressure of the driving fluid is low and the entrainment ratio is small correspondingly. It has little practical application and it was not valuable enough to practice. So almost all researches on operating conditions are focus on working fluid rather than driving fluid. There were few researches to study the effects of working fluid and ejector under similar pressure (big driving fluid pressure) on the ejector's behaviour, but the compress/ejector refrigeration system have posed the problem.

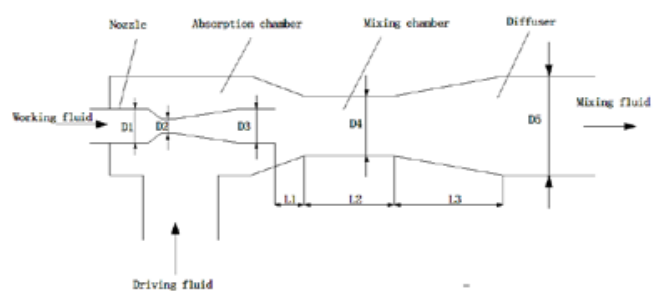

Fig.1 Schematic diagram of typical ejector

$$
\mu=\frac{G_{1}}{G_{2}},
$$




$$
C O P=\frac{Q_{\mathrm{e}}}{Q_{\mathrm{g}}+W_{\mathrm{p}}},
$$

$\mathrm{G}_{1}, \mathrm{G} 2$ are the fluxes of working fluid and driving fluid; $\mathrm{Q}_{\mathrm{e}}, \mathrm{Q}_{\mathrm{g}}, \mathrm{W}_{\mathrm{p}}$ are the capacity of ejector refrigeration system, input power of engine, energy losses of mechanical pump (negligible).

Sokolov, et al ${ }^{[5]}$ proposed a solar energy compress/ejector refrigeration system in 1990, in which a mechanical compressor (figure 2) was added between evaporator and ejector in the conventional ejector refrigeration system to improve the driving fluid pressure, thus enhancing the performance of the whole refrigeration cycle system. It combined advantages of mechanical compression refrigeration cycle and steam jet refrigeration cycle. It can not only use low enthalpy heat source but also has high thermal efficiency.

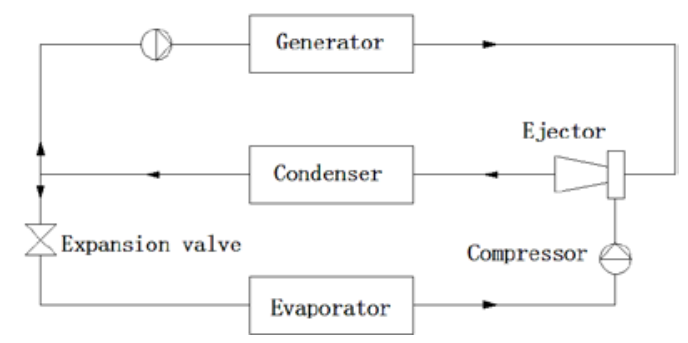

Fig.2 Compress/ejector refrigeration system

Chengchow Fang et al ${ }^{[6]}$ from Tianjin University did the related experimental study on solar compress/ejector refrigeration. Experimental results have shown that: under the conditions of $90^{\circ} \mathrm{C}$ generation temperature, $12^{\circ} \mathrm{C}$ evaporation temperature and $2000 \mathrm{~W}$ refrigerating capacity, the COP of the refrigeration system can reach 0.334 which was about $50 \%$ higher than the traditional pure jet refrigeration cycle $\mathrm{COP}(\leq 0.23)$, indicating great research value of the compress/ejector refrigeration system. This refrigeration system was mainly used to enhance the pressure of driving fluid. So the studding on driving fluid based on it are particularly important. This paper intends to analyse the driving fluid pressure and other working conditions which affect the performance of ejector through the two-dimensional CFD model.

\section{Numerical method}

Ejector model is calculated according to the theory of one dimensional design ${ }^{[6]}$.The detail parameters of ejector model are listed in table 1. The inner flow complies with nonlinear compressible and steady turbulent flow control equations. The standard K- $\varepsilon$ model is selected as turbulence model after comparison with the experiments results and having high precision and short calculation time. Ammonia was selected as the refrigerant. Driving fluid and wording fluid inlet conditions are pressure inlet boundary condition, and the exit is also set as outlet boundary conditions. All residual of the equation of continuity is $10^{-4}$, residual of turbulent kinetic energy and turbulence dissipation rate is $10^{-6}$.

The simulation results are largely influenced by meshing. Due to the irregular ejector structure, unstructured quadrilateral grid is adopted to the ejector to achieve better precision (figure 3). According to the grid independent test results, it can be seen that grid refinement has little impact on the results of simulation when the CFD model is meshed more than 30000 units. So we selected the grid which has 32053 units in total and 31005 quadrilateral grid in it. There are 29903 (96.44\%) units with the grid quality between 0.95 to 1 ensuring the good quality of grids. The fluid velocity is supersonic and the maximum speed can reach $2300 \mathrm{~m} / \mathrm{s}$, thus high quality of wall grid is needed. In order to have the better quality of grid, the wall grids and the boundary grids between driving fluid and working fluid are partial densified (figure 4) so that high speed of iteration and good simulation accuracy of the ejector model can be well guaranteed simultaneously.

Table 1: Ejector's structure parameters

\begin{tabular}{|c|c|c|c|c|c|c|c|c|}
\hline Parameters & D1 & D2 & D3 & D4 & D5 & L1 & L2 & L3 \\
\hline Dimension(mm) & 7.5 & 2 & 8 & 19 & 38.5 & 14 & 140 & 180 \\
\hline
\end{tabular}


Fig.3 Ejector grids

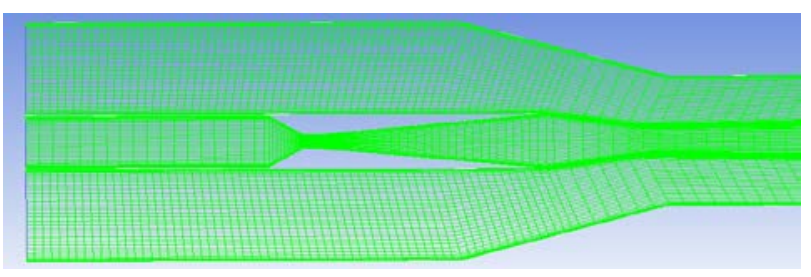

Fig.4 Partial enlarged detail of ejector inlet grids

The basic assumptions used during calculation in the CFD model are as follows:

The driving fluid and working fluid are not mixed before entering the absorption chamber; 2 . All of the working fluid, driving fluid and mixed fluid has uniform physical property at any cross section in ejector;3. The flow process in the nozzle and diffuser is adiabatic and isentropic; 4.The surface resistance of ejector wall would be ignored.

\section{Simulation and results}

With the ejector outlet pressure and working fluid pressure being constant, the entrainment ratio will change as driving fluid pressure changes. In order to find out the specific relations between entrainment ratio and driving fluid pressure, simulation of the working fluid is carried out as follows, and the outlet pressure $\mathrm{P}_{\mathrm{c}}$, working fluid pressure $\mathrm{P}_{1}$ and driving fluid pressure $\mathrm{P}_{2}$ are set as table 2. The relationship between driving fluid pressure and the entrainment ratio is shown in figure 5.

Table 2: Working conditions parameters

\begin{tabular}{|c|c|c|c|}
\hline Pc/MPa & 0.3 & 0.3 & 0.3 \\
\hline P1/MPa & 0.4 & 0.6 & 0.8 \\
\hline P2/MPa & $0.1,0.2,0.3,0.4$ & $0.1,0.2,0.3,0.4,0.5,0.6$ & $0.1,0.2,0.3,0.4,0.5,0.6,0.7,0.8$ \\
\hline
\end{tabular}

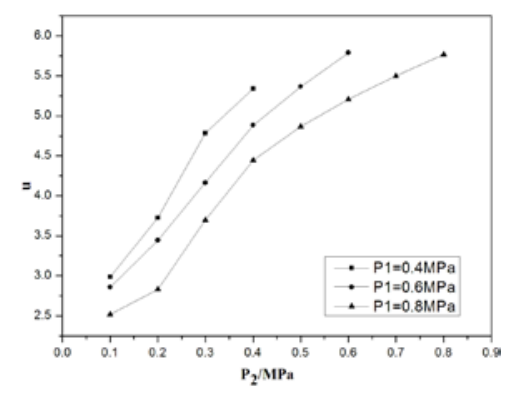

Fig.5 Driving fluid pressure and u

Analysis:

As we can see from the Fig. 5, with the $\mathrm{P}_{2}$ increases, entrainment ratio increases gradually at the same time. It can be seen from the velocity diagram (Fig. 6) that under constant working fluid and outlet pressure, as the driving fluid pressure $\mathrm{P}_{2}$ increases, the effective area of driving fluid in the mixing chamber increases. It means that the driving fluid flow increases in the ejector and entrainment ratio also increases correspondingly. However the improvement of driving fluid pressure would be limited in practical applications. On the one hand, it would increases energy consumption and the maintenance cost, on the other hand, the velocity of driving fluid will increase with the pressure. However, the entrainment would disappear when the velocity of driving fluid becomes higher than that of the working fluid ${ }^{[8]}$.The velocity distribution are shown in figure 6 under the condition of $\mathrm{P}_{1}=0.4 \mathrm{MPa}, \mathrm{P}_{\mathrm{c}}=0.3 \mathrm{MPa}, \mathrm{P}_{2}=0.1,0.2,0.3,0.4 \mathrm{MPa}$ respectively. It also can be seen that when $\mathrm{P}_{2}$ is $0.3 \mathrm{MPa}$, the driving fluid velocity is $809 \mathrm{~m} / \mathrm{s}$ and working fluid velocity is $720 \mathrm{~m} / \mathrm{s}$ in the entrance of mixing chamber. It is obvious that driving fluid velocity is greater than the working fluid. 
Similarly, fixing the pressure $\mathrm{P}_{1}=0.6 \mathrm{MPa}, \mathrm{Pc}=0.3 \mathrm{MPa}$, when $\mathrm{P}_{2}=0.5 \mathrm{MPa}$, the driving fluid velocity is $1715 \mathrm{~m} / \mathrm{s}$, working fluid velocity is $1451 \mathrm{~m} / \mathrm{s}$ in the entrance of mixing chamber. It can be seen that driving fluid velocity is greater than that of the working fluid. Equally, $\mathrm{P}_{1}=0.8 \mathrm{MPa}, \mathrm{P}_{\mathrm{c}}=0.3 \mathrm{MPa}$, when $\mathrm{P}_{2}=0.7 \mathrm{MPa}$, the driving fluid velocity is $1971 \mathrm{~m} / \mathrm{s}$, which is bigger than the working fluid velocity $1731 \mathrm{~m} / \mathrm{s}$, there comes the similar result.

The velocity distribution also shows that when the driving fluid pressure increases, the velocity of driving fluid increases when entering the mixing chamber. It can be seen that driving fluid velocity is greater than the speed of working fluid when the $\mathrm{P}_{1}$ minus $\mathrm{P}_{2}$ is about $0.1 \mathrm{MPa}$ so that the phenomenon of entrainment of working fluid would disappear. Although entrainment ratio can be improved by levelling up the driving fluid pressure, the ejector refrigeration system performance COP will no longer improves because at this moment the ejector is only used as a pipeline when the velocity of driving fluid is high ${ }^{[8]}$. As a result, to achieve better performance, it is suggested to make the driving fluid pressure about $0.1 \mathrm{MPa}$ lower than that of the working fluid. This conclusion provides valuable guiding for the working fluid and driving fluid pressure setting.

3.2 Entrainment ratio magnitude increases greatly when $\mathrm{P}_{2}=\mathrm{P}_{c}$ from the observation of Fig 6 . According to equation (1) and the flux distribution results in ejector, it can be found that when $\mathrm{P}_{1}=0.4 \mathrm{MPa}, \mathrm{P}_{2}=\mathrm{P}_{\mathrm{c}}=0.3 \mathrm{MPa}$, Entrainment ratio raises from 3.73 to 4.79 ; when $\mathrm{P}_{1}=0.6 \mathrm{MPa}$, $\mathrm{P} 2=\mathrm{P}_{\mathrm{c}}=0.3 \mathrm{MPa}$, Entrainment ratio raises from 3.44 to 4.17 ; when $\mathrm{P}_{1}=0.8 \mathrm{MPa}, \mathrm{P}_{2}=\mathrm{P}_{\mathrm{c}}=0.3 \mathrm{MPa}$, Entrainment ratio raises from 2.83 to 3.70 .

In order to verify the conclusion mentioned above, following simulations are made as follow, working fluid is in constant pressure, driving fluid pressure $\mathrm{P}_{2}$ is $1 \mathrm{MPa}$ and $\mathrm{P}_{c}$ is $0.3,0.5,0.7 \mathrm{MPa}$ respectively. The relationship between driving fluid pressure and entrainment ratio can be observed clearly.

It is obvious that entrainment ratio magnitude increases greatoy when $\mathrm{P}_{2}=\mathrm{P}_{\mathrm{c}}=0.3,0.5,0.7 \mathrm{MPa}$ are sportively and the same conclusion can be found when $\mathrm{P}_{1}=0.8 \mathrm{MPa}$.

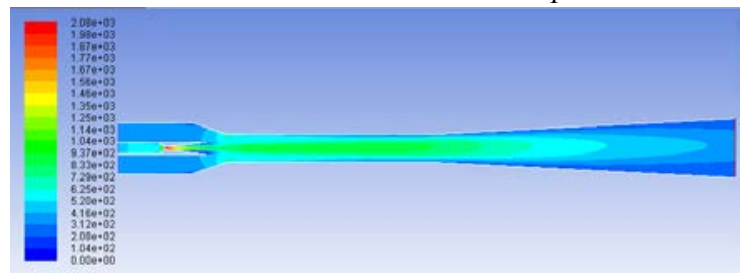

(a) $\mathrm{P} 2=0.1 \mathrm{MPa}$

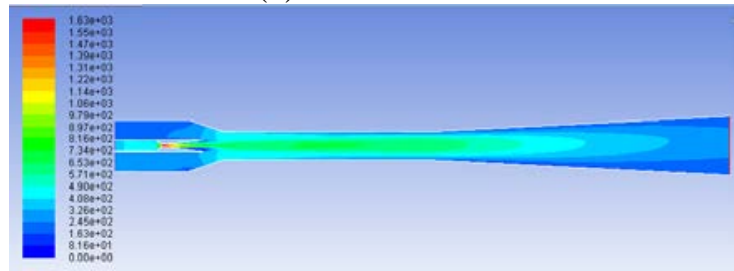

(b) $\mathrm{P} 2=0.2 \mathrm{MPa}$

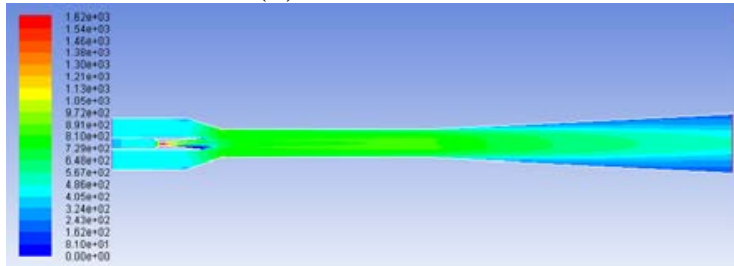

(c) $\mathrm{P} 2=0.3 \mathrm{MPa}$

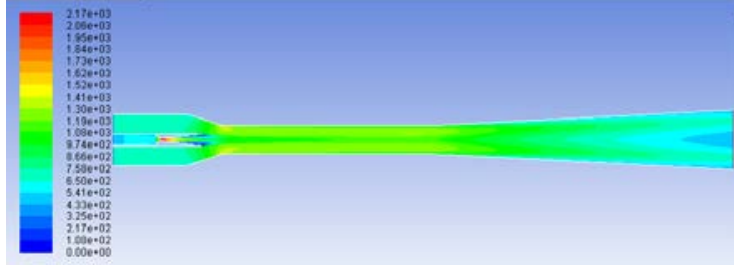

(d) $\mathrm{P} 2=0.4 \mathrm{MPa}$

Fig.6 Velocity chart under $\mathrm{P} 1=0.4 \mathrm{MPa}, \mathrm{Pc}=0.3 \mathrm{MPa}$ 


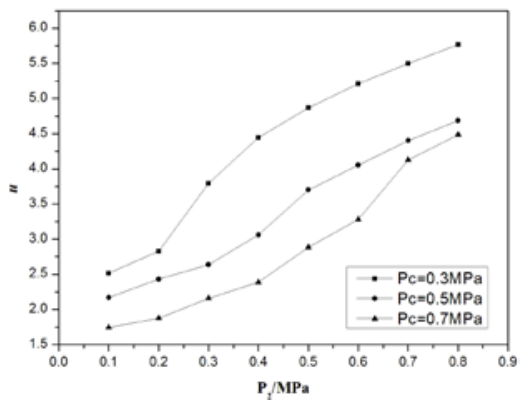

Fig.7 Driving fluid pressure and u under $\mathrm{P} 1=0.8 \mathrm{MPa}, \mathrm{P} 2=\mathrm{Pc}$

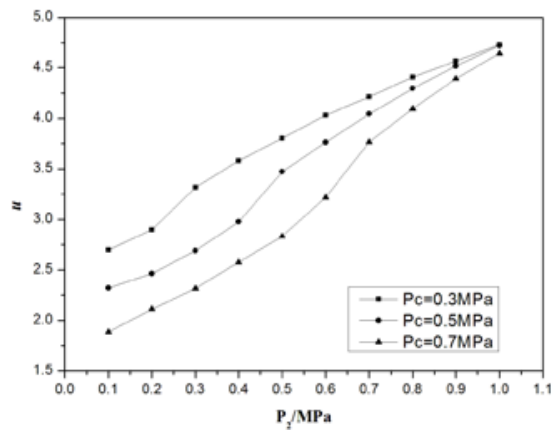

Fig.8 Driving fluid pressure and u under $\mathrm{P} 1=1 \mathrm{MPa}, \mathrm{P} 2=\mathrm{Pc}$

\section{Conclusion}

With the increasing of driving fluid pressure $\mathrm{P}_{2}$, entrainment ratio will increase gradually. However, when the driving fluid pressure increases to about 0.1 MPa lower than working fluid pressure, driving fluid velocity will be bigger than the working fluid. Although the entrainment ratio will improve with the increasing of driving fluid pressure, the entrainment effect of working fluid will disappear and the performance of ejector system cannot be further improved and cost of system maintenance will increase due to high pressure. In summary, we could make sure that the driving fluid pressure is about $0.1 \mathrm{MPa}$ lower than the working fluid so that ejector can achieve optimal performance.

Entrainment ratio magnitude will reach the maximum when P2=Pc under the constant working fluid pressure. We can also achieve the optimal entrainment ratio under low pressure.

\section{Reference}

[1]Yang Yan-qin, A Zhi-qiang \& Jing Shu-dong. Effects of nozzle exit position, area ratio and driving fluid pressure to the ejector performance [J].Chemical Equipment Technology, 2006, 27(1): p. 68-72.

[2]Xu Hai-tao \& Sang Zhi-fu. Effect of structure parameters to the ejector compressor [J].Journal of Nanjing university of technology (natural science edition), 2003, 25(3): p. 28-33.

[3]Xu Hai-tao \& Sang Zhi-fu. The thermodynamic model entrainment ratio calculation of steam jet refrigeration system [J].Journal of Chemical Engineering, 2004, 55(5): p. 704-710.

[4]T. Sriveerakul, S. Aphornratana \& K. Chunnanond. Performance prediction of steam ejector using computational fluid dynamics: Part 2. Flow structure of a steam ejector influenced by operating pressures and geometries [J]. International Journal of Thermal Sciences.Volume46.Issue 8.2007.823-833.

[5]M. Sokolov \& D. Hers gal. Enhanced ejector refrigeration cycles powered by low grade heat. Part1. Systems characterization. International Journal of Refrigeration, Volume 13, Issue 6, Pages p. 351-356. 
[6]Zhao Jun etc. Research on compress/ejector refrigeration system by using low enthalpy energy [C]. Academic conference of engineering thermodynamics and energy utility of Chinese thermal physics academy. 1993: 6.

[7]Chandra, Vineet V. Ahmed \& M. R. Experimental and computational studies on a steam jet refrigeration system with constant area and variable area ejectors [J].Energy Conversion and Management.Volume79.2014. 377-386.

[8]Yao Yun, Bi Rong-shan \& Gu Xin-chun. Analysis of gas fluid two phase flow in ejector refrigeration system [J].Journal of computational and applied chemistry, 2008, 25(5):583-586. 